Published in final edited form as:

Thromb Res. 2014 May ; 133(0 1): S18-S20. doi:10.1016/j.thromres.2014.03.011.

\title{
Roles of PAR1 and PAR2 in Viral Myocarditis
}

\author{
Nigel Mackman and Silvio Antoniak \\ Department of Medicine, Division of Hematology and Oncology, UNC McAllister Heart Institute, \\ University of North Carolina at Chapel Hill, 98 Manning Drive Campus Box 7035, Chapel Hill, \\ North Carolina, USA
}

\section{Abstract}

Viral myocarditis is estimated to cause $\sim 20 \%$ of sudden death in people under the age of 40 . A variety of viruses have been found to cause myocarditis including coxsackievirus B3 (CVB3). Many studies have been performed with CVB3 because there is a mouse model of CVB3-induced myocarditis. Studies have shown that the TLR3-IFN $\beta$ pathway plays a central role in the innate immune response to CVB3 infection. Our laboratory studies the role of protease activated receptors (PAR) in different biological responses including viral infection. We examined the effect of a deficiency in either PAR1 or PAR2 on CVB3-induced myocarditis. Interestingly, we found that PAR1 knockout mice had increased cardiac injury whereas PAR-2 knockout mice had decreased cardiac injury. Our studies support the notion that PARs modulate the innate immune response and can have both positive and negative effects on TLR-dependent responses.

\section{Keywords}

viral infection; innate immune response; protease activated receptor; proteases; myocarditis; coxsackievirus B3

\section{Viral Myocarditis}

Myocarditis can be caused by viral infections of the heart. A variety of viruses have been proposed to cause myocarditis, including enteroviruses and adenoviruses. Coxsackievirus B3 (CVB3) is a single-stranded (ss) RNA enterovirus of the Picornaviridae family. It was one of the first viruses identified to cause myocarditis [1,2]. Importantly, there is a mouse model of CVB3-induced myocarditis that can be used to study the innate immune response to the virus. Myocarditis can be divided into three phases: early, acute and late phases [3]. In the early phase of infection the virus itself causes cardiac injury by infection of cardiac cells. In the acute phase, the infection is detected by the innate immune system and immune cells

(C) 2014 Elsevier Ltd. All rights reserved.

Address for Correspondence: Nigel Mackman, PhD, University of North Carolina at Chapel Hill, 98 Manning Drive Campus Box 7035, Chapel Hill, North Carolina, 27599, Telephone: (919) 843 3961, Fax: (919) 966 7639, nmackman@ med.unc.edu.

Competing Interests Statement: none

Publisher's Disclaimer: This is a PDF file of an unedited manuscript that has been accepted for publication. As a service to our customers we are providing this early version of the manuscript. The manuscript will undergo copyediting, typesetting, and review of the resulting proof before it is published in its final citable form. Please note that during the production process errors may be discovered which could affect the content, and all legal disclaimers that apply to the journal pertain. 
are recruited to the heart to kill infected cells and limit viral replication. However, the immune cells themselves can increase cardiac injury [4]. In the late phase the virus is eliminated although viral genomes may persist in the heart. Loss of myocardium after infection leads to remodeling and fibrosis that is associated with impaired heart function and in severe cases heart failure [2].

\section{Innate immune response in viral myocarditis}

Invading pathogens are rapidly detected by the innate immune system. Pathogen-associated molecular patterns (PAMPs) are detected by pattern recognition receptors (PRRs), such as Toll-like receptors (TLRs) [5]. Viral infections are mainly detected by the endosomal TLRs that are activated by nucleic acids, including TLR3, TLR7, TLR8 and TLR9. Doublestranded (ds) RNA is formed in the cytoplasm during the replication of ssRNA viruses such as CVB3. Other PRRs involved in the detection of viral infections include the cytoplasmic receptors melanoma differentiation-associated gene 5 and retinoic acid-inducible gene 1 [6]. The adaptive immune system also plays a major role in host defense against viral infection $[7,8]$.

Mouse models of CVB3-induced myocarditis have shown a key role of TLR3 and a downstream adaptor protein in the innate immune response to infection $[9,10]$. Activation of TLR3 leads to expression of interferons (IFNs) that coordinate the early antiviral response of the innate immune system [10]. Type I (IFNa and IFN $\beta$ ) but not type II or III IFNs are required for an effective early response to CVB3 infection [11, 12]. Cardiac cells express low levels of IFNa and IFN $\beta$ but expression is increased after viral infection. IFNs are also expressed by immune cells. Type I IFNs expressed by cardiac cells are essential to limit myocarditis [13]. IFNs induce the expression of IFN-stimulated genes (ISGs) that limit replication of the virus and recruit immune cells. These ISGs include $2^{\prime}-5^{\prime}$ oligoadenylate synthetase/RNase L that limits CVB3 replication and various chemokines, such as CXCL10 $[11,12]$. NK cells play an important role in limiting the spread of the infection [14].

\section{Protease-activated receptors}

Protease-activated receptors (PARs) are a family of 7 membrane spanning, G-protein coupled receptors [15]. There are 4 members of the family and they are activated by a variety of proteases. This allows cells to sense changes in their extracellular environment. For instance, thrombin generated in the coagulation cascade activates human platelets by cleavage of PAR1. Interestingly, mouse platelets do not express PAR1 but are activated by thrombin via a PAR3/PAR4 complex [16]. PAR2 is activated by several proteases, such as trypsin and tryptase, but not by thrombin [17]. PAR1 and PAR2 are widely expressed in different cells in the body. Importantly, studies have shown that PAR1 and PAR2 signaling can be pro-inflammatory and anti-inflammatory depending on the disease model [18]. One of the challenges in studying PARs in vivo is determining which protease(s) is activating a given PAR. 


\section{Crosstalk between PARs and TLRs}

An early study showed that PARs play a role in the innate immune response to fungal infection [19]. PAR-dependent signaling was affected by TLR expression/activation and vice versa [19]. Interestingly, PAR1 and PAR2 had opposite effects. PAR1 promoted inflammation in response to Candida in a TLR2-dependent manner, whereas PAR-2 attenuated inflammation in response to Aspergillus in a TLR4-dependent manner [19]. The authors proposed that PARs and TLRs act as a dual-sensor system during infections where TLRs are activated by PAMPs and PARs are activated by extracellular proteases from the host and the pathogen [19]. Importantly, another study showed that co-stimulation of PAR2 and TLR4 in a human colonic epithelial cell line led to synergistic induction of the chemokine IL-8 [20]. Furthermore, PAR2 and TLR4 were found to physically interact after PAR2 stimulation [20, 21]. A subsequent paper from the Vogel group showed that PAR2 signaling promoted an anti-inflammatory Th2 response in LPS stimulated murine macrophages [22]. A further study found co-operative signaling between PAR2 and TLR2, TLR3 and TLR4 for activation of NF- $\kappa B$ and IL-8 expression [23]. However, activation of PAR2 negatively regulated TLR3-dependent IFN $\beta$ expression and ISGs, such as CXCL10 and RANTES, in mucosal epithelial cell lines [23]. Similarly, the Riteau group found that activation of PAR2 reduced RANTES expression in A549 cells infected with H1N1 influenza A [24]. These data indicated that PAR2 signaling suppresses the TLR3-dependent antiviral pathway.

\section{Virus Life Cycle}

In general, the viral life cycle can be divided into virus entry/infection, virus replication/ assembly and virus release/shedding. CVB3 infection is facilitated by coxsackievirusadenovirus receptor and the decay-accelerating factor on the cell surface and subsequent endocytosis [2]. Changes in virus receptor expression and/or endocytosis may reduce virus uptake. PARs are internalized by endocytosis and enhance this process after activation [25]. We showed that PAR2 deficiency reduced CVB3 infection and replication in vitro [21].

After virus uptake, the virus has to be unpacked, viral genomes replicated and components assembled to form new viral particles. This stage is dependent on the cell cycle stage and p53 expression/activity [26]. IFN $\beta$ and ISGs reduce viral replication [11]. We and others showed that PAR1 enhances and PAR2 decreases IFN $\beta$ and ISGs expression after TLR3 stimulation in vitro [21, 23, 27]. We also observed that CVB3 replication in vitro was reduced in PAR2 deficient cardiac cells due to increased IFN $\beta$ expression [21]. In addition, recent findings have linked p53 to TLR signaling and innate immune responses [28]. Interestingly, PAR1 activation on epithelial cells was shown to increase p53 expression [29] and p53 is known to inhibit CVB3 replication [26, 30, 31].

The last phase of the viral life cycle is the release of infectious particles. Viral particle release is often mediated by cell lysis or budding from the membrane. PAR1 activation has been linked to increased membrane budding which may enhance virus dissemination [32]. 


\section{Role of PAR2 in CVB3 infection}

Based on in vitro studies showing PAR2 negatively regulated TLR3-dependent IFN- $\beta$ expression, it was expected that PAR2 deficient mice would be protected from viral infections that involved TLR3. We collaborated with Dr. Rauch's group to analyze the effect of PAR2 deficiency on CVB3 infection. We found that PAR2 deficient mice were protected from CVB3-induced myocarditis compared to wild-type controls [21]. Infected PAR2 deficient mice had a significantly increased IFN $\beta$ mRNA expression and reduced viral load and inflammation. In vitro studies with murine embryonic cardiac fibroblasts demonstrated that PAR2 deficient cells expressed higher levels of IFN $\beta$ and the chemokine RANTES after CVB3 infection or stimulation with the dsRNA mimetic polyinosinic acid:polycytidylic acid (poly I:C) compared with wild-type cells [21]. Furthermore, PAR2 activation inhibited poly I:C stimulation of Stat-1 phosphorylation, which is activated downstream of the IFN receptor and is required for expression of ISGs. We conclude that PAR2 signaling suppresses TLR3-dependent antiviral response to two different ssRNA viruses. At present we do not know the protease that activates PAR2 in CVB3-induced myocarditis.

\section{Role of PAR1 in CVB3 infection}

We determined the effect of PAR1 stimulation on TLR3-dependent IF- $\beta$ and CXCL10 expression in murine embryonic cardiac fibroblasts. We found that activation of PAR1 increased TLR3-dependent IFN $\beta$ and CXCL10 expression in a p38-dependent manner [27]. As expected, PAR-1 deficient cells failed to respond to a PAR1 agonist peptide and expressed lower levels of IFN $\beta$ and CXCL10. These results indicated that PAR1 positively contributed to the antiviral response of cardiac fibroblasts and predicted that PAR1 deficient mice would be more susceptible to viral infection compared with wild-type controls. Indeed, we observed that PAR1 deficient mice expressed lower levels of IFN $\beta$ and CXCL10 early after CVB3 infection and had higher viral genomes and inflammation in the acute phase of infection. Furthermore, PAR1 deficient mice had increased cardiac injury 8 days after infection and decreased cardiac function at 28 days after infection compared with wild-type mice [27]. Interestingly, mice overexpressing PAR1 on cardiomyocytes were protected from CVB3-induced myocarditis. These transgenic mice exhibited increased levels of IFN $\beta$ expression and reduced levels of virus and reduced cardiac injury [27]. These observations are consistent with a role of PAR1 in the innate immune response to viral infection. Our studies suggest that both thrombin and matrix metalloproteinase 13 activate PAR1 during CVB3 infection [27].

\section{Conclusions}

We and others have shown that PAR1 and PAR2 affect to the host response to viral infection by modulating TLR3 signaling. Further studies are needed to analyze the role of PARs in different virus infections. There are many open questions about the role of PARs during virus infections. What is the primary activator of PAR2 in CVB3 infection? A possible source for a PAR2 activator could be mast cells. Another question is how do PAR1 modulate TLR signaling and the innate immune response in different cell types. We are currently analyzing the effect of cell type-specific deletion of PAR1 in cardiac fibroblasts or 
cardiomyocytes on CVB3-induced myocarditis to identify the primary site of protective PAR1 signaling. Another important question is how do PARs modulate TLR signaling. The most likely possibility is by altering different intracellular signaling pathways. Another question is do PARs modulate other PRRs? Clearly there is much work to be done in this field.

\section{Acknowledgments}

This work was supported by grants from the Myocarditis Foundation (S.A.) and the National Institutes of Health (N.M).

\section{References}

1. Schultheiss HP, Kuhl U, Cooper LT. The management of myocarditis. European heart journal. 2011; 32:2616-25. [PubMed: 21705357]

2. Blauwet LA, Cooper LT. Myocarditis. Progress in cardiovascular diseases. 2010; 52:274-88. [PubMed: 20109598]

3. Antoniak S, Boltzen U, Riad A, Kallwellis-Opara A, Rohde M, Dorner A, Tschope C, Noutsias M, Pauschinger M, Schultheiss HP, Rauch U. Viral myocarditis and coagulopathy: increased tissue factor expression and plasma thrombogenicity. Journal of molecular and cellular cardiology. 2008; 45:118-26. [PubMed: 18495150]

4. Antoniak S, Mackman N. Coagulation, Protease-Activated Receptors, and Viral Myocarditis. Journal of cardiovascular translational research. 2013

5. Thompson JM, Iwasaki A. Toll-like receptors regulation of viral infection and disease. Advanced drug delivery reviews. 2008; 60:786-94. [PubMed: 18280610]

6. Koyama S, Ishii KJ, Coban C, Akira S. Innate immune response to viral infection. Cytokine. 2008; 43:336-41. [PubMed: 18694646]

7. Kemball CC, Alirezaei M, Whitton JL. Type B coxsackieviruses and their interactions with the innate and adaptive immune systems. Future microbiology. 2010; 5:1329-47. [PubMed: 20860480]

8. Huber S. Host immune responses to coxsackievirus B3. Current topics in microbiology and immunology. 2008; 323:199-221. [PubMed: 18357771]

9. Abston ED, Coronado MJ, Bucek A, Bedja D, Shin J, Kim JB, Kim E, Gabrielson KL, Georgakopoulos D, Mitzner W, Fairweather D. Th2 regulation of viral myocarditis in mice: different roles for TLR3 versus TRIF in progression to chronic disease. Clinical \& developmental immunology. 2012; 2012:129486. [PubMed: 22013485]

10. Riad A, Westermann D, Zietsch C, Savvatis K, Becher PM, Bereswill S, Heimesaat MM, Lettau O, Lassner D, Dorner A, Poller W, Busch M, Felix SB, Schultheiss HP, Tschope C. TRIF is a critical survival factor in viral cardiomyopathy. J Immunol. 2011; 186:2561-70. [PubMed: 21239721]

11. Wessely R, Klingel K, Knowlton KU, Kandolf R. Cardioselective infection with coxsackievirus B3 requires intact type I interferon signaling: implications for mortality and early viral replication. Circulation. 2001; 103:756-61. [PubMed: 11156890]

12. Deonarain R, Cerullo D, Fuse K, Liu PP, Fish EN. Protective role for interferon-beta in coxsackievirus B3 infection. Circulation. 2004; 110:3540-3. [PubMed: 15249500]

13. Stewart MJ, Smoak K, Blum MA, Sherry B. Basal and reovirus-induced beta interferon (IFN-beta) and IFN-beta-stimulated gene expression are cell type specific in the cardiac protective response. Journal of virology. 2005; 79:2979-87. [PubMed: 15709018]

14. Godeny EK, Gauntt CJ. Murine natural killer cells limit coxsackievirus B3 replication. J Immunol. 1987; 139:913-8. [PubMed: 3036947]

15. Coughlin SR. Thrombin signalling and protease-activated receptors. Nature. 2000; 407:258-64. [PubMed: 11001069]

16. Nakanishi-Matsui M, Zheng YW, Sulciner DJ, Weiss EJ, Ludeman MJ, Coughlin SR. PAR3 is a cofactor for PAR4 activation by thrombin. Nature. 2000; 404:609-13. [PubMed: 10766244] 
17. Antoniak S, Pawlinski R, Mackman N. Protease-activated receptors and myocardial infarction. IUBMB life. 2011; 63:383-9. [PubMed: 21438116]

18. Shpacovitch V, Feld M, Bunnett NW, Steinhoff M. Protease-activated receptors: novel PARtners in innate immunity. Trends in immunology. 2007; 28:541-50. [PubMed: 17977790]

19. Moretti S, Bellocchio S, Bonifazi P, Bozza S, Zelante T, Bistoni F, Romani L. The contribution of PARs to inflammation and immunity to fungi. Mucosal immunology. 2008; 1:156-68. [PubMed: 19079173]

20. Rallabhandi P, Nhu QM, Toshchakov VY, Piao W, Medvedev AE, Hollenberg MD, Fasano A, Vogel SN. Analysis of proteinase-activated receptor 2 and TLR4 signal transduction: a novel paradigm for receptor cooperativity. The Journal of biological chemistry. 2008; 283:24314-25. [PubMed: 18622013]

21. Weithauser A, Bobbert P, Antoniak S, Bohm A, Rauch BH, Klingel K, Savvatis K, Kroemer HK, Tschope C, Stroux A, Zeichhardt H, Poller W, Mackman N, Schultheiss HP, Rauch U. Proteaseactivated receptor 2 regulates the Innate Immune Response to Viral Infection in a CVB3-induced Myocarditis. Journal of the American College of Cardiology. 2013; 62:1737-45. [PubMed: 23871888]

22. Nhu QM, Shirey KA, Pennini ME, Stiltz J, Vogel SN. Proteinase-activated receptor 2 activation promotes an anti-inflammatory and alternatively activated phenotype in LPS-stimulated murine macrophages. Innate immunity. 2012; 18:193-203. [PubMed: 21239455]

23. Nhu QM, Shirey K, Teijaro JR, Farber DL, Netzel-Arnett S, Antalis TM, Fasano A, Vogel SN. Novel signaling interactions between proteinase-activated receptor 2 and Toll-like receptors in vitro and in vivo. Mucosal immunology. 2010; 3:29-39. [PubMed: 19865078]

24. Khoufache K, LeBouder F, Morello E, Laurent F, Riffault S, Andrade-Gordon P, Boullier S, Rousset P, Vergnolle N, Riteau B. Protective role for protease-activated receptor-2 against influenza virus pathogenesis via an IFN-gamma-dependent pathway. J Immunol. 2009; 182:7795802. [PubMed: 19494303]

25. Chignard M, Pidard D. Neutrophil and pathogen proteinases versus proteinase-activated receptor-2 lung epithelial cells: more terminators than activators. American journal of respiratory cell and molecular biology. 2006; 34:394-8. [PubMed: 16547194]

26. Lazo PA, Santos CR. Interference with p53 functions in human viral infections a target for novel antiviral strategies? Reviews in medical virology. 2011

27. Antoniak S, Owens AP 3rd, Baunacke M, Williams JC, Lee RD, Weithauser A, Sheridan PA, Malz R, Luyendyk JP, Esserman DA, Trejo J, Kirchhofer D, Blaxall BC, Pawlinski R, Beck MA, Rauch U, Mackman N. PAR-1 contributes to the innate immune response during viral infection. The Journal of clinical investigation. 2013; 123:1310-22. [PubMed: 23391721]

28. Takaoka A, Hayakawa S, Yanai H, Stoiber D, Negishi H, Kikuchi H, Sasaki S, Imai K, Shibue T, Honda K, Taniguchi T. Integration of interferon-alpha/beta signalling to p53 responses in tumour suppression and antiviral defence. Nature. 2003; 424:516-23. [PubMed: 12872134]

29. Suzuki T, Yamashita C, Zemans RL, Briones N, Van Linden A, Downey GP. Leukocyte elastase induces lung epithelial apoptosis via a PAR-1-, NF-kappaB-, and p53-dependent pathway. American journal of respiratory cell and molecular biology. 2009; 41:742-55. [PubMed: 19307610]

30. Hwang HY, Kim JY, Lim JY, Chung SK, Nam JH, Park SI. Coxsackievirus B3 modulates cell death by downregulating activating transcription factor 3 in HeLa cells. Virus research. 2007; 130:10-7. [PubMed: 17599613]

31. Munoz-Fontela C, Macip S, Martinez-Sobrido L, Brown L, Ashour J, Garcia-Sastre A, Lee SW, Aaronson SA. Transcriptional role of p53 in interferon-mediated antiviral immunity. The Journal of experimental medicine. 2008; 205:1929-38. [PubMed: 18663127]

32. Vemuri GS, Zhang J, Huang R, Keen JH, Rittenhouse SE. Thrombin stimulates wortmannininhibitable phosphoinositide 3-kinase and membrane blebbing in CHRF-288 cells. The Biochemical journal. 1996; 314(Pt 3):805-10. [PubMed: 8615773] 


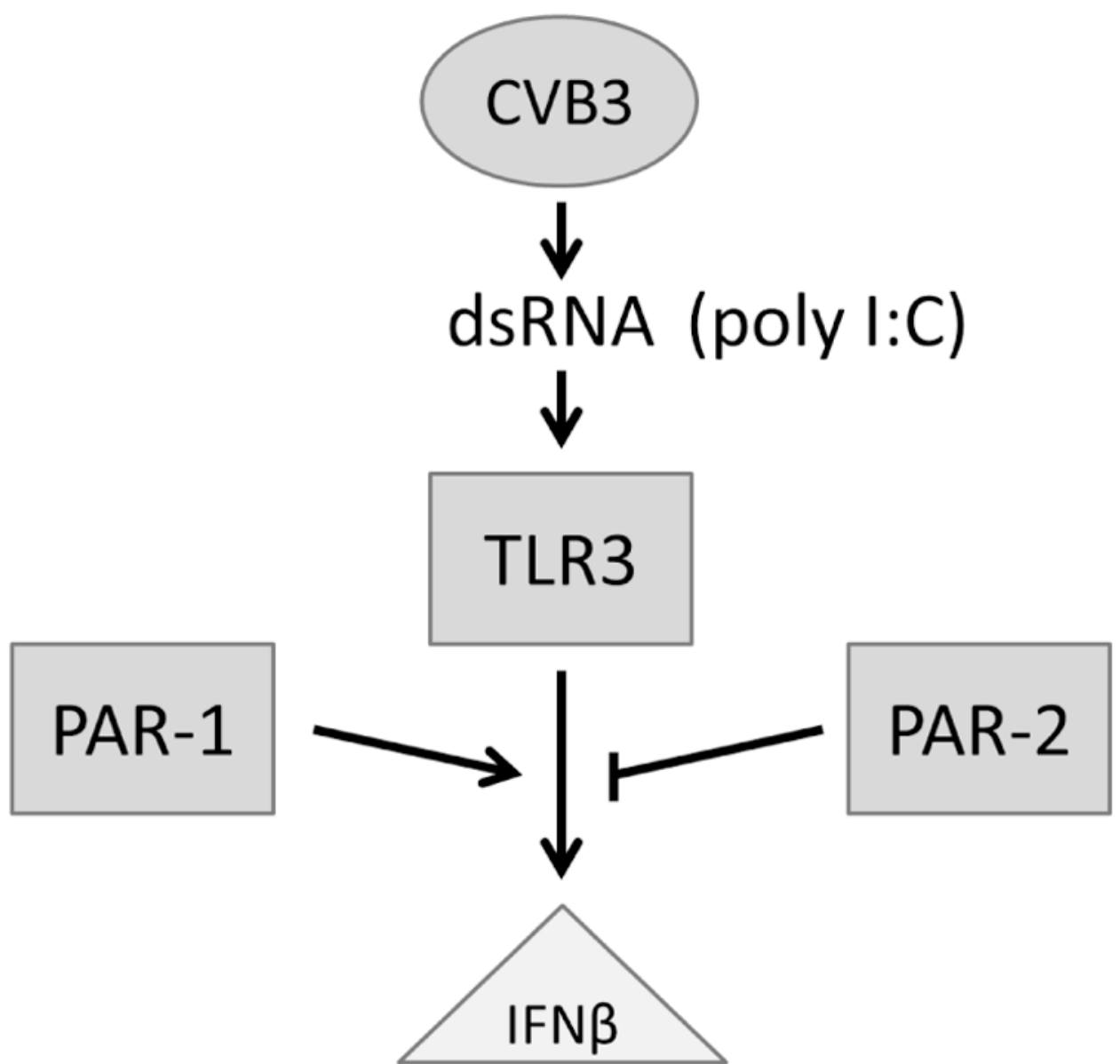

Figure 1. Mackman and Antoniak TR

Effect of PAR1 and PAR2 activation on TLR3-dependent IFN $\beta$ expression. CVB3 infection of cells leads to the generation of dsRNA stimulates TLR3 resulting in IFN $\beta$ expression as part of the antiviral response. The dsRNA mimetic poly I:C can be used to stimulate TLR3. In cardiac fibroblasts activation of PAR-1 enhances whereas activation of PAR-2 suppresses TLR3 induction of IFN- $\beta$ expression. 